Helen Higgins

East Riding County Council

\&

Anthea Gulliford, University of Nottingham.

Address:

School of Psychology

University Park

University of Nottingham.

Nottingham

NG7 2RD

anthea.gulliford@nottingham.ac.uk 


\title{
Understanding Teacher Assistant self-efficacy in role and in training: its susceptibility to influence
}

\begin{abstract}
There has been a noted growth in the number of teaching assistants (TAs) in mainstream schools (DfE, 2013a). Research is inconclusive about their efficacy at changing outcomes for children (Alborz et al 2009; Blatchford et al, 2009) and has proposed more training for TAs (Russell et al, 2005). Generic training models have suggested that enhancing self-efficacy in turn improves performance. This exploratory study investigated factors that may influence TAs' sense of self-efficacy and its susceptibility to influence in training. Following two modes of mode of school-based training by Educational Psychologists (EPS) data were collected from 14 mainstream secondary school TAs using focus groups. A thematic analysis noted themes regarding self-efficacy, aligned with Bandura's (1977) sources of information, outcome expectations and whole school support and norms. Review of the data is likely to be able to guide potential trainers to coach consult strategies which are self-efficacy supportive and which address contextual factors including the perceived status of TAs in schools.
\end{abstract}

Keywords:

Teaching Assistant

Self-efficacy

Training

Coach consult

Role

School

Effectiveness 


\section{Introduction.}

\section{Increasing number of TAs and TA effectiveness}

'Schools of the future would be rich in trained adults available to support learning to new higher standards' (Estelle Morris, Secretary of State for Education and Skills, 2001 p.19). As Estelle Morris (2001) predicted British schools now have a raised level of support staff. According to the last Department for Education statistics (DfE, 2013a), between 2000 and 2012 the number of TAs working in England (in mainstream primary, nursery and secondary schools/ academies) has almost tripled with an increase in numbers from 79,000 to 232,300. This raises the question of how their contribution can be best defined and understood.

Groom (2006) noted a growing area of research looking at the impact of TAs, and this has explored questions of role, efficacy and training. To date the research has been equivocal on how TAs contribute most effectively in schools, and where that impact may be seen. Brown and Harris's (2009) data suggested that the presence of TAs can be associated with increased GCSE scores, for example, whereas several studies have indicated that the presence of TAs does not correlate with increased academic attainment (Muijs and Reynolds, 2003; Blatchford, Russell, Bassett, Brown, and Martin, 2007; Blatchford Martin, Moriaty, Bassett and Goldstein, 2002). Other research suggests that TAs may improve on task behaviour (Blatchford, Bassett, and Brown, 2005), support inclusion (Lacey, 2001) and reduce teachers' administrative jobs (Gunter et al, 2005). Alborz, Pearson, Farrell and Howes' (2009) systematic review of the research suggested that "TAs appear effective when trained and supported to deliver specific interventions" (p.15). However, significantly, the Deployment and Impact of Support Staff (DISS) project concluded that individual children with SEN supported by TAs made significantly less progress than similar children who were not supported (Blatchford et al, 2009), and other researchers have argued that TAs may often be considered obstacles between the children they are supporting and their peers (Farrell, Balshaw and Polat, 1999; Groom, 2006). Overall, the literature has highlighted concerns regarding the efficacy and attunement of TA contributions. 
Together with the DfE's focus upon impact (DfE, 2013b), this places the question of creating effective outcomes for children through the TA role at the forefront of TA research. Significantly, Blatchford, Russell and Webster (2012a) argued in their Effective Deployment of Teaching Assistants (EDTA) project that the apparent lack of progress shown in the DISS project was not the fault of the TAs but due to the issues associated with the deployment, practice and preparedness of the TAs. They proposed that changes to these three areas would increase the effectiveness of TAs on pupil performance. All of this points to the need for a considered approach to skill development and professional role development for TAs.

\section{TA role, skills and training}

Attention has been paid by several researchers to the nature and ambiguity of the TA role and training within role (Farrell, Balshaw and Polat, 2000; Groom, 2006, Blatchford et al, 2007). Survey and observation data suggests that TAs spend the majority of their time working directly with children, described as a 'Wider Pedagogical Role' (Blatchford et al, 2012a). Research over the past 20 years has also indicated that a large proportion (at least 59\%) of TAs enter the profession at either GCSE level or below (Blatchford, Webster and Russell, 2012b; Russell et al, 2005; Clayton, 1990). Although the majority of TAs complete some training specific to the role, this has often been described as 'patchy' and not necessarily leading to qualifications (Russell, Blatchford, Bassett, Brown and Martin, 2005).

Blatchford et al (2012a) argued these issues relating to training are part of the lack of 'preparedness' that TAs face, which they suggest negatively influence child outcomes. 'Preparedness' includes skill and professional role development noted by a number of authors (The Plowden Report, Central Advisory Council For Education 1967; Warnock, 1978; Moran and Abbott, 2002). The findings from the ETDA project (Blatchford et al, 2012a) suggested that $70 \%$ of school leaders (e.g. head teachers) felt that TAs preparedness was improved through targeted training and discussions with teachers or SEN specialists. However, this view was not shared by teachers and TAs, who suggested that other factors such as TAs 'tuning in' to teachers' talk improved preparedness more (Webster, Blatchford and Russell, 2012). Cajkler, Tennant, Tiknaz and Sage's (2007) systematic review of studies where TAs had been trained noted a significant number of papers where TA performance improved following training. Factors underpinning any change in behaviour explored in these articles included improvement in TA self esteem and confidence. Within Cajkler et al's review 29/81 
studies also focused on TAs' self esteem and confidence following training, as a training outcome. The themes of increasing TA confidence and self esteem continues to be echoed by more recent researchers (Webster et al, 2012; Butt and Lowe, 2012). However Cajkler et al (2007) particularly highlighted three studies that indicated that despite positive changes in knowledge, skills, self esteem and confidence, TAs' behaviour and performance within the teaching and learning process did not change (Edwards and Clemson, 1997: Hutchings, 1997: Swann and Loxley, 1998). One author (Hutchings, 1997) suggested that lack of change in TA performance was due to external factors such as a lack of opportunity given to the TAs by the teachers to demonstrate their new skills. Hayes, Richardson, Hindle and Grayson (2011) concluded that TA self-efficacy was a factor which influenced their implementation of a Video Interaction Guidance intervention. They also suggested that TA self-efficacy is influenced by training opportunities.

The influence of the socio-political context of the school upon the delivery of the TA role has been noted. Taylor and Gulliford (2011) identified the subtle but significant influences on Nurture Group provision staffed by TAs as opposed to teachers, where for example, TAs were not involved in formal meetings with parents on the child's entry to the nurture group. There was a noted impact upon the subsequent development of the partnership between home and school. This in turn raised questions regarding the empowerment of TAs in the wider school structure. Green (2013), in a study of intervention implementation and outcome for CBT groups in schools highlighted the need for TAs to have careful and ongoing support in the planning and delivery of programmes. Training TAs upon an intervention's core content was not sufficient to ensure their confident delivery of a 10 week programme, or full adherence to the programme's core principles in the scaffolding of students. Empowerment of TAs within the wider ecology of the school, then, has been noted as important to the ultimate effectiveness or otherwise of interventions, reflecting a wider understanding that a practitioner's capacity to respond to training has a relationship with features of the organisation (Butterfoss, Kegler, and Vincent 2008). Research therefore highlights both the issue of increasing confidence and self esteem of TAs through training and the possible external and organisational factors that may impact on effective TA performance and children's outcomes (Blatchford et al, 2012a). However, this specific focus on the role and functioning of TAs themselves within and following training is rare within research.

\section{Training and self-efficacy}


Studies of training and continuing professional development (CPD) for any professionals note, amongst other aspects, the need for recipients of training to optimise their experience and move from being recipients of training, to actors, where implementation of new knowledge and skills becomes possible (Lave and Wenger 1991; Opfer and Pedder, 2011; Turner, Nicholson and Sanders, 2011). Typically, following training, behaviour change and adaptation to delivery of new work patterns is seen as non-automatic and problematic. Balchin, Randall and Turner (2006) addressed this is using a coach consult training model, which aimed to develop the sense of mastery and self-efficacy of individual staff (see below).

A strong relationship has been outlined in the literature between performance and selfefficacy (Enderlin-Lampe, 2002). Penrose, Perry and Ball (2007) asserted that raising teacher self-efficacy would have a better effect on pupil outcomes than working through models of school effectiveness. Equally, Enderlin-Lampe (2002) argued that within a learning organisation framework reforms which focus on empowering self-efficacy staff are a key part of effective schools.

\section{Self efficacy}

The earliest self-efficacy research focused on Rotter's (1966) locus of control theory. A person's level of self-efficacy will be determined by whether they have an internal or external explanation for outcomes of tasks and/or and responsibilities. While Bandura defined selfefficacy as "beliefs in one's capabilities to organise and execute the course of action required to produce given attainment." (p3 Bandura 1977) He viewed it as a behavioural change based on a cognitive motivation construct.

Most self-efficacy theories based on Bandura's premise refer to some extent to two factors; efficacy expectancy and outcome expectations. Efficacy expectancy is the belief in one's capacity to influence an outcome. Outcome expectancy is the belief that if effort is applied an expected outcome will be achieved (Tobin, Muller and Turner, 2006). The interaction of these two factors and the perceived self-efficacy process is shown in figure 1.

\section{Figure 1 about here.}

Bandura's (1977) asserted that self-efficacy beliefs are developed through four different sources of information and through twelve different modes of induction (see table 1). 


\section{Table 1 about here}

Bandura (1977) argued that enactive mastery experience/ performance accomplishment is the most influential on self-efficacy. He further stated that perceived self-efficacy is domain specific and situational and can therefore change over time and in different contexts. Furthermore, self-efficacy can change in three different dimensions (Bandura, 1977):

- Strength (the degree to which efficacy could be modified)

- Generality (how it can be applied to various situations)

- Magnitude (the amount of effort put into the task)

Enderlin-Lampe (2002) captured Bandura's different sources of self-efficacy and the different ways people could respond to a certain situation in a model which locates perceived self-efficacy as the pivotal feature. This is argued to be fed on the one hand by: performance accomplishment (achievements); vicarious learning (apprenticeship experiences); verbal persuasion; and emotions arousal, on the one hand. Perceived self-efficacy is also influenced by how the individual exercises choice (engaging versus avoiding) performance (linked to effort and intensity) and persistence.

Enderlin-Lampe's (2002) model is useful at explaining what a person might do if they have a high or low level of self-efficacy. For example, if a person has a high level of self-efficacy because they have had a previous success in a task (performance accomplishment) then they may choose to approach the next task and may also persist with it if it becomes difficult and may also put more effort into their performance of the next task. In contrast if a person has a low level of self-efficacy, they may choose to avoid the task or not persist or put much effort into their performance especially if the task becomes difficult.

\section{TA and teacher self-efficacy}

Whilst there are calls for the enhancement of TA skills and self-efficacy, direct research into TA self-efficacy is difficult to find. It is useful, therefore, to review the work of those who have reviewed empirical evidence and theories relating these issues to the teacher role (Hammett and Burton, 2005). 
Teacher self-efficacy has been defined as "the extent to which teachers believe their efforts will have a positive effect on their students' abilities, in redirecting their students' behaviour and on their overall student achievement" (Tobin et al, 2006 p. 303). Teacher self-efficacy research is a contentious area, with debate regarding the theoretical construct of teacher selfefficacy and regarding the validity of the numerous teacher self-efficacy scales (Denzine, Cooney and McKenzie, 2005, Skaalvik and Skaalvik, 2007). However, there is broad agreement that self-efficacy can be understood as being grounded in predominantly in two theoretical perspectives; Bandura's self-efficacy theory and Rotter's locus of control theory (Denzine et al, 2005, Skaalvik and Skaalvik, 2007).

\section{Factors influencing teacher self-efficacy}

Studies have noted factors which can contribute to teacher self-efficacy. Successful prior experience working with children with special educational needs (Gibbs, 2007), working with parents (Soltys, 2005; Skaalvik and Skaalvik 2010) and in behaviour management (Giallo and Little, 2005) are such examples. In addition, pre-service teacher training with parents (Soltys, 2005), behaviour management and interventions (Giallo and Little, 2005; Wade, 2003) and special educational needs (Gibbs, 2007; Sachs, 1988) have been identified. However, the nature of training and how teachers' professional needs are met are important considerations (Opfer and Pedder 2011; Tebbs, 2001). Collaborative and supportive training is suggested to be more likely to develop positive self-efficacy than simple group training (Gibbs, 2007). Sachs (1988) directly linked aspects of teacher training programmes with Bandura's sources of information and modes of induction (Table 1).

Erdem and Demirel (2007) argue that often there is a 'sink or swim' approach to teacher training, detrimental to self-efficacy. This echoes Sachs' (1988) argument that self-efficacy should be developed during pre-service training and not as damage control during in-service training. Tobin et al (2006) make the case for teacher self-efficacy being developed not only through individual training but also through organisational initiatives. Contextual factors within an organisation such as participation, framing and organisational climate will influence the outcome of training and interact with a person's self-efficacy (Quinones, 1997).

Returning to the question of TA self-efficacy, there have been several studies that have directly focused or commented on contextual factors that influence TAs' feelings of job satisfaction, stress and motivation. Butt and Lance's (2005) noted some a decline in TA job 
satisfaction but a majority (65\%) were generally satisfied and motivated in their jobs. Areas of TA dissatisfaction included conditions of services; such as temporary contracts, low pay and lack of training opportunities alongside some issues of disorganisation and feeling unprepared (Russell et al, 2005, Clayton, 1993, Farrell et al, 2000). Hammett and Burton (2005) surveyed TAs on different aspects of the job. They discovered that a clear career progression, specialist roles and training would be seen as motivating factors for TAs. However, they concluded that schools should focus on activities that will increase TAs' selfesteem and status, emphasising that "people who feel that they have very little influence over their work behaviour can experience a de-motivating lack of involvement in their work" (p.300).

The need, then, to understand self-efficacy in TAs, and how it might potentially be influenced through training approaches led to the study reported below. The data reported here is one element of a comparative research project, exploring outcomes from different TA training methods, but the wider study is not described below. Here, the focus is primarily upon illumination of TA self-efficacy: its sources and potential malleability in training.

\section{Method}

\section{Objectives of the present study}

The aim of the study was to explore sources of influence upon TA self-efficacy and its susceptibility to influence through training approaches. This study formed part of a larger piece of research exploring the impact of training on TAs' behaviour, learning and selfefficacy (Higgins, 2009).

\section{Design of the study}

The design of the study was flexible using qualitative methodology and thematic analysis of the data gathered. In flexible designs the researcher is the key instrument in the process and needs to be open and responsive to data. Analytic or theoretical generalisation from the data is possible though inductive theory building (Robson, 2002).

Exploratory methods were selected for this question, in contrast to the majority of studies advancing empirical insights into the concept of self-efficacy. Whilst controlled designs allow for causal inferences, qualitative approaches were preferable here because of this 
investigation's focus upon the rich detail of perceptions available from participants following an intervention, and because of the small-scale localised nature of the study.

\section{Participants and sampling}

The sample frame of TAs was drawn from three secondary schools from small rural market towns/ villages in the same geographical location. The TAs were chosen to take part in the training by the SENCo in the school. The number of TAs during the majority of the training was in School A: 3, School B: 8, School C: 6. At the stage of data collection three TAs from School B decided not to take part. Therefore the sample was voluntary non-probability sample (though this cannot be known for sure due to the socio political nature of schools). This type of sampling method is adequate in flexible designs provided that there is no intention to generalise to the population from the data (Cohen, Manion and Morrison, 2007).

\section{Procedure}

The training was negotiated between the Head Teacher and SENCo of the schools and the EPs author involved.

\section{Training intervention}

School A and School B both took part in six sessions of training using the coach consult method (Balchin et al, 2006) spread over two terms. This approach involves principles, drawing upon Bandura's (1977) sources of information and modes of induction but no set format or method. Therefore the implementation of this model in the study, below, is the researcher's interpretation of these principles. The coach consult method was used in order to deliver an approach which was likely to be highly self-efficacy supportive, and enable a comparison (not reported here) with traditional training methods. The training process outlined here was as follows:

1. Needs assessment: enactive mastery- self instructed performance

Through EP consultations with the TAs, training needs associated with behaviour management skills were identified and session timetables were set up. Therefore the training schedule was individual in each school but with some sessions overlapping.

2. Training methods: vicarious experiences- live modelling; verbal persuasionsuggestion 
The training methods used in the sessions emphasised practical application and were based on constructive methods such as coaching and mentoring. Sessions involved modelling and scaffolding of skills, role play as well as time to practice these skills.

3. Implementation: enactive mastery: performance desensitisation; performance exposure

The emphasis in this training approach was for the TAs to develop their skills and knowledge, in order to empower themselves and the students they work with. Therefore between sessions there was an expectation that TAs would try the new skills.

4. Recap and reflection: enactive mastery- self-instructed performance; physiological arousal

Each subsequent session started with a recap of the previous session and a reflection on the TAs' implementation of these skills, focusing on what went well and what they would do differently next time.

5. Adaptive curriculum: enactive mastery- self-instructed performance

Consultations and needs assessments continued during the sessions to adapt the curriculum to fit the changing needs of the TAs.

School A and B covered topics in training which were related to behaviour management. The TAs in School C were given a one off INSET training session about the Breakwell (1997) Assault Cycle as this was one of the topics covered in both School A and School B during the coach consult training sessions. The sources of information and modes of induction used in this INSET training were vicarious experiences- live modelling and verbal persuasionsuggestion.

\section{Data collection}

TAs took part in one of three 45-minute focus group meetings in their respective schools, approximately two months after the completion of training. The researcher utilised the methods discussed in Kitzinger (1995), Vaughn, Jeanne Shay Schumm and Sinagub (1996), Krueger and Casey (2000) alongside the research relating to self-efficacy to produce a script for the focus group interview. Attention was paid to issues of reliability and validity in generating focus group data. Ground rules were used, and the researcher was sensitive to the size of group, familiarity of staff, and the need to distribute opportunity within the discourse, through facilitation (Cohen et al 2007). The data were recorded, transcribed, and coded by the 
researcher using inter-rater checks. Anonymity and confidentiality of the data was securely maintained and the audio tapes were erased after their use. Ethical issues within their process were addressed through explanatory letters and debriefing to all relevant school staff.

\section{Analysis of data: Thematic analysis}

To analyse qualitative data in this study a thematic analysis was carried out on the transcriptions. Braun and Clarke (2006) proposed that there are many different techniques of thematic analysis. They have argued that because of this, researchers have debated the validity of this type of analysis. To reduce validity issues of interpretation and theory and to ensure a robust analysis, steps outlined by Vaughan et al (1996) on how to analyse focus group interviews were used. The steps used were:
a) Coding data
b) Deciding on categories and inclusion criteria for these categories and placing quotes into envelopes
c) Reviewing these categories in an iterative process
d) Developing themes from these categories
e) A colleague completing these steps and the themes compared
f) Final themes developed

\section{Results and Discussion: factors affecting TA self-efficacy}

The thematic analysis highlighted three main influences on self-efficacy which could be categorised as: Bandura's (1977) theory of sources of information; outcome expectations; and whole school support and norms (see figure 2).

\section{Figure 2 about here}

Some aspects of the sources of information theme relate to those features of the training which impacted self-efficacy, supporting Sachs' (1988) case that Bandura's (1977) model can be adopted in teacher training. Bandura (1997) argued that performance accomplishment/ enactive mastery has the greatest effect on self-efficacy. The majority of TAs referred at some point to previous experience with children as affecting their behaviour, for example. The most common response in this category related to the relationship they have developed 
with children, with many stating that if they or others had a positive relationship with children, they were more likely to be successful.

TA 5: "knowing what will work with them."

Some of the TAs responses indicated that the specific training approach that was employed, coach consult, affected their behaviour.

TA 8: "the second time I did think about it and get it right eventually."

Whereas one TA in the comparison group (standard training) stated that she found the situation false.

TA 9: "putting into implementation was difficult, it was quite a false situation."

Additionally, TAs who subsequently trained or supported other TAs following the EP training referred to helping others which they felt increased their confidence. The TAs in School A all referred to the cascade training they provided to other TAs.

TA 1: "going and showing the others how to do it....TA3: doing it as an INSET helped .... reinforced what we learnt."

and two TAs in school B mentioned how helping others made them feel more confident.

TA 8: "it does boost your confidence to think that you've helped somebody else."

Several of the TAs also referred to how learning from others, vicarious learning, made them feel more confident to do the intervention and the TA role in general.

TA 1: "yeah and we learn them from each other all of the time, well I do."

TA 4: "well for me I couldn't have done it without C's worksheet thing today."

TA 8: "I think it is because you'd seen how someone else works doing it, and everybody learns from everyone else."

Many of the TAs mentioned how verbal persuasion from the trainer or the other TAs had affected their confidence.

TA 2: "this is what I do this is why I do it, it helps it really does." 
TA 5: "working in the small group situation as well... you can hear different points of view... someone might have done something else that you have not thought about and you can think hang on a minute that could work for my student."

and several also mentioned how their emotions or physiological state affected their confidence with the intervention and with the work in general.

TA 1: "I was terrified the first time."

TA 2: "yeah it depends on how drained you are... you could have had a bad day and you wouldn't have been in there quite as long or a rough day when you just need a break."

This theme did not state specifically which source of information was most powerful for the TAs or whether all of the TAs were influenced by all four of Bandura's (1977) categories. However, since there was a reference to all four sources of information there is an indication that they had some effect on the TAs confidence, behaviour and self-efficacy.

The category outcome expectations referred to the effects the TAs believed that the TA role could have on students. This varied between the TAs and some highlighted very pupilspecific factors as affecting how they viewed their effectiveness. Some also stated that they could make a difference but that this depended on the context, with different TAs citing different contextual factors.

One TA stated that the age of the student meant that she could not have an effect.

TA 13: "I think the older ones understand that but some of the younger ones don't sort of always see where they've gone wrong. "

Whereas another TA stated that she could make a difference if the problem was due to the home environment, but she might not be able to make a difference if the student had autism.

TA 4: "I think the kid with autism, it's a lot more difficult than when their problems are more environmental."

Some TAs stated they could make a difference if they had home support.

TA 10 "I think you can contain behaviour in school to a point but you... can't always change someone's core values because they are given by the parents." 
TA 12: "yeah I think you can at school... definitely but then it they go home and their parents are saying what a load of rubbish or you don't have to listen to them."

However, other TAs stated that they could make a difference. Though, the difference might be quite small or only happen when the student grows up.

TA 4: "it will rub off, hopefully they will take it on into their adult life."

TA 5: "it is going to have some kind of input into their life even if they think it is a negative or a positive."

Finally there were some TAs who referred to making no difference.

TA 7: "you can't win unless they want to I mean if the student is not going to change... no matter what you do or how much you bend over backwards for them."

TA 12: "there are some students that no matter how hard you try, if they don't want to, they're to be in the right place haven't they."

This theme was illuminated by the literature on teacher self-efficacy (Denzine et al 2005; Skaalvik and Skaalvik, 2007) and Bandura's (1977) original theory, which suggested that self-efficacy is partly influenced by the outcome expectations of the individual. Despite some similarities, outcome expectations are highly individual. TA self-efficacy, here, appears to be influenced by what outcome expectations they believe they can achieve. These outcome expectations, in turn, seem to be influenced by different factors as well. Firstly, they seem to be influenced by how much the TAs themselves perceive they can influence change.

TA 12: "yeah I think you can at school."

Or whether it is luck or determination/ effort that could make a difference

TA 4: "it will rub off."

TA 7: “you can't win."

Similarly, TAs appear to be influenced by their values or concepts about how children change: whether children change due to their age, maturation, home background or genetic composition or indeed whether change is possible at all. These values and beliefs highlight TA attributions regarding children, similar to the teacher attribution theory suggested by Miller (2003).

Whole school support and norms (such as school climate and organisational issues) . 
This captured the organisational factors that influenced the TAs self-efficacy. Many of these can be seen in the contextual elements referred to by Quinones (1997). Here, TAs, refer to the organisational climate and the value placed on TAs within that climate of the school. There were several subthemes which referred to organisational issues that would hinder TAs' confidence and self-efficacy. Although there were common themes, the whole school support needs and focuses of the different schools seemed to be quite individual and not unexpectedly reflected the individual nature of each school organisation. TAs in all schools, however, implied that their self-efficacy would increase if whole school norms were developed through whole school training and development of practices.

TA 3: "just keeping up to speed with it and putting on training... yes because we had the knowledge before it started in school."

TA 5: "I think looking at the behaviour in school I think the school need to look at having people doing this kind of work with students."

This subtheme may highlight the importance of a school developing as a learning organisation and for the TAs to be part of this (Butterfoss et al 2008).

Some of the TAs did not feel that there were enough resources in the school for them to successfully do their job.

TA 3: "but that's staffing isn't it, that we need to sit down and sort that out."

TA 12: “a room... you don't want to sit in the canteen and talk with people coming in and out. You can't do it in the corridors obviously, the LSU is often full, so where do you go?"

Finally, TAs from all three focus groups referred to the time pressures that they have within the school and how this possibly impaired their performance.

TA 3: "last year... we were a bit more flexible... I was I had a bit more time personally being able to do it, well this year with change of staff and such like and more responsibilities, I haven't done any."

TA 1: "it is building and building at the minute." 
TA 7: "we did not have enough time."

These subthemes echo Shapiro, Schwartz and Astin (1996) question of whether developing self-efficacy is always valuable in uncontrollable situations. Arguably, when TAs feel that the organisation has the positive norms, for example, and sufficient resources available then they may feel that they can make a difference and their self-efficacy will be high. However, when there are conflicting values within the school and limitations of time and resources then they are likely to feel less able to control the situation to make a difference, leading to low selfefficacy.

Other subthemes within the overall category of whole school support and norms reflected how the TAs perceived they were valued within the school. Some TAs from School A and School B referred to valuing themselves within the organisation helped them to feel confident. Several of the TAs in School A felt that they did not get paid comparatively well for the good job they were doing.

TA 1: “(pay) doesn't affect how I do my job but it is beginning to affect how I feel.... TA2: I think it does particular."

TA 2: "the staff that earn a lot of money come and work in our this building here don't interact with the children at all ... do they need to go on a course that which encourages them to work with you know the kids with the challenging behaviour."

The last quote could indicate that the TA values the 'hands on' role of working with children and possibly believes that higher paid staff do not value this role. Russell et al (2005) suggested that TAs' job satisfaction could be influenced by factors such as low pay.

Some TAs referred to valuing their own skills and learning within the context of the school environment.

TA 3: "but if you were teaching a lesson you would go and do your lesson, wouldn't you. Maybe we (should) do that, it is what we are doing and we will do it. Allocate that hour."

TA 2: "it's an open book really isn't it and it's evolving, it's up to the individual what they want to do how far they would want to take it."

Many of the TAs in School B did not feel valued by the some of the teachers 
TA 8: "unless someone listens to us and we say... we're not going to actually achieve anything from this even though we feel we are doing well."

TA 7: "that's the problem we can say something and then sometimes it doesn't make a difference. We are undermined on a regular basis."

Whereas some of the TAs in School A referred to feeling valued and supported by teachers and how this helped them to feel confident in their role.

TA 3: "once they have sent someone out of their lesson and their lesson goes well they will sent them out again and you kind of make a rod for your own back because if you have got work out of them then you take that back, they think I've had a lovely lesson, they have got some work done, why not do that again."

As Quinones (1997) points out that when a person feels that they are not part of or valued within an organisation, the outcome of any training will be affected.

\section{Conclusions}

The data here suggested that TA self-efficacy could be understood through three themes: Bandura's (1977) theory of sources of information, outcome expectations and whole school support and norms. The first theme, Bandura's (1977) theory of sources of information, highlights the importance of the processes of training and nature of experience (Tebb, 2001; Gibb, 2007; Hayes et al, 2011). Training can be influenced by verbal persuasion from others, emotion or affect as well as learning from others' experience. Engaging in first-hand experience of an intervention, showing others how to do something and having experience of working with children also seem to be important sources of information that have a potneial impact on TA self-efficacy.

The outcome expectations themes illuminated the potential effects of individualised perceptions and values that the TAs are bringing to the role. Each TA employed in a school may have a very different view of how much influence they can have with the children. It may be necessary for schools to explore these values and challenge unhelpful beliefs. Whilst TAs outcome expectancies may change depending on their experiences in their role, and indeed training, they may also be affected their sense of control and this is shown to relate to the school environment. 
The final theme, whole school support and norms outlines contextual factors and draws attention to those features of the school organisation that potentially influences TA selfefficacy (Quinones, 1997). However, TA self-evaluation and sense of worth, again highly individualised, was linked to previous experiences and personality traits. This supports Carlson, Buskis and Martin (2000) argument that self-efficacy models should include more emphasis on personality traits and early developmental history.

The combination of themes about self-efficacy identified in this study may interact with each and could be depicted as shown in figure 3 .

\section{Figure 3 about here}

\section{Implications of the study}

\section{The importance and development of self-efficacy in TAs}

Studies reviewed above have highlighted the rationale for raising TA self-efficacy in contributing ultimately to student outcomes, yet noted the need for doing so in conjunction with attending to features of the school context which facilitate TA practice (Cajkler et al 2007). This parallels insights from other domains, primary health prevention, for example, where the conditions for uptake of evidence-based interventions have been noted to be the program itself, the implementers, and the context (Turner et al 2011). The data in this study suggests a framework to support schools in developing TA self- efficacy and in turn their effectiveness and overall school improvement. The qualitative data here provides insights into factors that contribute to the development of TA self-efficacy in training contexts as well as within a school environment. These factors included:

- Creating conditions during training opportunities and within the school environment that give TAs: positive experiences, vicarious learning, verbal support and 'persuasion' and positive physiological conditions

- Developing positive relationships with staff and children

- Developing whole school practices which include TAs

- Have the right amount of resources

- Helping TAs to develop a perception of the controllability of outcomes for students While EPs may be well placed to work directly with schools at an organisational and school improvement level, approaches to organisational development and change have shown that training per se cannot achieve this. This study highlights how EPs may support the 
development of practices which aim to enhance TA self-efficacy, increasing the likelihood of longitudinal change. This

could be achieved through training approaches with staff similar to the methods used in this study, or consultation with senior management highlighting the school improvement benefits of improving staff self-efficacy levels. Where resources and funding for TAs are more centrally controlled, EPs are also well placed within local authorities to help develop practices that would enhance self-efficacy.

\section{Different training approaches influence of self efficacy}

Although the aim of this paper was not to compare the two training approaches used in the overall study, the coach consult method appears to contain more elements of Bandura's sources of information and modes of induction than regular INSET training (see table 2). Sachs linked aspects of teacher training programmes to Bandura's theories related to self efficacy. It is possible to link aspects of the coach consult model and of INSET training to Bandura's modes of induction and sources of information. TAs alluded to all of Bandura's sources of information as having an influence on their self efficacy, suggesting that methods which address vicarious learning models, verbal 'persuasion' coaching, and implementation models, could have a more powerful influence on TA self efficacy than regular INSET training. Bandura (1997) argues that performance accomplishment/ enactive mastery has the greatest impact on self efficacy and there are several elements built within the coach consult method such as the needs assessment, implementation, recap and reflection and adaptive curriculum stages that may give TAs opportunities to develop enactive mastery and specifically have the chance to practice and reflect on the interventions discussed during the direct training. This hypothesis would benefit from further research, to guide EPs and other practitioners to appropriate models of 'consultative training' and to explore the specific features of such models associated with self-efficacy enhancement, and changes in practice. However, this study would suggest that EPs should consider reviewing their current training approaches and ensure that they are not only improving staff's knowledge of a topic but also their selfefficacy.

Table 2 about here 


\section{Developing a TA self efficacy scale}

Finally, to support further research into TA self efficacy, a domain specific TA self efficacy scale would be helpful (Brouwers and Tomic, 2001). The scale might be based solely on the three themes, Bandura's sources of information, outcome expectations and whole school norms and support. However, the emphasis shown by TAs with regards to their relationships and knowledge of students and the organisational factors and norms that impinged on their feelings of self-efficacy indicates consideration of these contextual elements. This study might suggest a TA scale based on a similar model to Cherniss's (1993) three-factor teacher scale, the Teacher Interpersonal Self-efficacy Scale, which specifically considered teacher self-efficacy with regards to:

1. Interpersonal domain

2. Task domain

3. Organisation domain

In this way, the contextualised nature of feelings of self-efficacy for practitioners shown in this data would be acknowledged. EPs conducting research could assist with the development of self-efficacy scales and reviewed different models and approaches in this topic. EPs are well place to ensure that evaluation of training methods assess whether self-efficacy is being enhanced during and after the training process as well as through practices within schools.

The authors would like to acknowledge the support of Nick Durbin, Craig Bridge and Nicki Hammill in the early phases of this work.

\section{References}

Alborz, A., Pearson, D., Farrell, P., \& Howes, A. (2009). The impact of adult support staff on pupils and mainstream schools. Technical Report. In Research Evidence in Education Library. London: EPPI-Centre, Social Science Research Unit, Institute of Education, University of London.

Balchin, N., Randall, L., \& Turner, S. (2006). The Coach Consult Method: A model for sustainable change in schools. Educational Psychology in Practice, 22 (3) 237-254

Bandura, A. (1977). Social Learning Theory. Englewood Cliffs, NJ: Prentice-Hall Inc

Bandura, A. (1997). Self-efficacy: Towards a unified theory of behavioural change. Psychological Review, 84, 191-215

Blatchford, P., Bassett, P., \& Brown, P. (2005). Teachers' and Pupils' behaviour in large and small classes: A systematic observation study of pupils aged 10 and 11 years. Journal of Educational Psychology, 97 (3) 454-467

Blatchford, P., Bassett, P., Brown, P., Martin, C., Russell, A., \& Webster, R. (2009). The deployment and impact of support staff project. Research summary. Short summary of the main findings, conclusions and recommendations from the DISS project. London: Institute of Education, London and DCSF 
Blatchford, P., Martin, C., Moriaty, V., Bassett, P., \& Goldstein, H. (2002). Pupil Adult Ratio Differences and Educational Progress over Reception and Key Stage 1. Norwich: DfES Research Report no. 335

Blatchford, P., Russell, A., Bassett, P., Brown, P., \& Martin, C. (2007). The role and effects of teaching assistants in English primary schools (Years 4-6) 2000-2003. Results from Class Size and Pupil-Adult Rations (CSPAR) Key Stage 2 Project. British Educational Research Journal, 33 (1) 5-26

Blatchford, P., Russell, A., \& Webster, R. (2012a). Reassessing the impact of teaching assistants: how research challenges practice and policy, Abingdon, UK: Routledge

Blatchford, P., Webster, R., \& Russell, A. (2012). Challenging the role and deployment of teaching assistants in mainstream schools: The impact on schools. Final report on findings from the Effective Deployment of Teaching Assistants (EDTA) project

Braun, V., \& Clarke, V. (2006). Using thematic analysis in psychology. Qualitative Research in Psychology, 3 (2) 77-101

Breakwell, G. M. (1997). Coping with Aggressive Behaviour. Oxford: Blackwell Publishing

Brouwers, A., \& Tomic, W. (2001). The Factorial Validity of Scores on the Teacher Interpersonal Self-Efficacy Scale. Educational and Psychological Measurement, 61, 433-445

Brown, J., \& Harris, A. (2009). Increased expenditure on Associate Staff in schools and changes in student attainment. Institute of Education, London: TDA and SSAT

Butt, G. and Lance, A. (2005) Modernizing the role of support staff in primary schools: changing focus, changing function. Educational Review, 57 (2) 139-149

Butt, R., \& Lowe, K (2012). Teaching assistant and class teachers: differing perspectives, role confusion and the benefits of skill-based training. International Journal of Inclusive Education, 16 (2) 207-219

Butterfoss, F. D., Kegler, M. C., \& Francisco, V. T. (2008). Mobilizing organizations for health promotion: Theories of organizational change. In K. Glanz, B. K. Rimer, \& K. Viswanath (Eds.), Health behavior and health education: Theory, research and practice (4th ed., pp. 335361). San Francisco, CA: Jossey-Bass.

Cajkler, W., Tennant, G., Tiknaz, Y., \& Sage, R. (2007). A systematic review on how training and professional development activities impact on teaching assistants' classroom practice (19882006). In: Research Evidence in Education Library. London: EPPI-Centre, Social Science Research Unit, Institute of Education, University of London.

Central Advisory Council For Education (England). Children and their primary schools [Plowden Report]. London: HMSO, 1967.

Carlson, N. R., Buskis, W., \& Martin, G. N. (2000). Psychology: The Science of Behaviour. London: Allyn and Bacon

Cherniss, C. (1993). Role of professional self-efficacy in the etiology and amelioration of burn-out. In W. B. Schaufeli, C. Maslach and T. Marek (eds) Professional burnout: Recent developments in theory and research. Washington DC: Taylor and Francis

Clayton, T. (1990). The training needs of special welfare assistants: what do heads, class teachers and the assistants themselves regard as important. Educational and Child Psychology, 7 (1) 44-51

Clayton, T. (1993). Welfare Assistants in the Classroom- Problems and Solutions. Educational Psychology in Practice, 8 (4) 191-197

Cohen, L., Manion, L., \& Morrison, K. (2007). Research Methods in Education. Abingdon: Routledge

Denzine, G. M., Cooney, J. B., \& McKenzie, R. (2005). Confirmatory factor analysis of the Teacher Efficacy Scale for prospective teachers. British Journal of Educational Psychology, 75, 699708 
Department for Education (2013a). School Workforce in England: November 2012. SFR15.2013. London: DFE.

Department for Education (2013b) Improving the quality of teaching and leadership https://www.gov.uk/government/policies/improving-the-quality-of-teaching-and-leadership

Edwards, E. \& Clemson, D. (1997) Reflections on the comparative roles of the NNEB Diploma in Nursery Nursing and the Specialist Teacher Assistant Certificate. Paper Presented at: British Educational Research Association Annual Conference. University of York: 11-14 September

Enderlin-Lampe, S. (2002). Empowerment: Teacher perception, aspirations and efficacy. Journal of Instructional Psychology, 29 (3) 139-146

Erdem, E., and Demirel, O. (2007). Teacher self-efficacy belief. Social Behavior and Personality, 35 (5), 573-586

Farrell, P., Balshaw, M., \& Polat, F. (1999). The Management, Role and Training of Learning Support Assistants. Norwich: DFEE Research Report No 161

Farrell, P., Balshaw, M., \& Polat, F. (2000). The work of learning support assistants in mainstream schools: Implications for educational psychologists. Educational and Child Psychology, 17 (2) 66-76

Giallo, R., \& Little, E. (2003). Classroom Behaviour Problems: The relationship between Preparedness, Classroom Experiences and Self-efficacy in Graduate and Student Teachers. Australian Journal of Educational and Developmental Psychology, 3, 21-34

Gibb, S. (2007). Teachers' perceptions of efficacy: Beliefs that may support inclusion or segregation. Educational and Child Psychology, 24 (3) 47-52

Green, Sarah. (2013) An Evaluation of a FRIENDS for Life Programme in a mainstream secondary school and its impact on emotional distress, anxiety, and coping skills. University of Nottingham. Unpublished DAppEdPsy thesis.

Groom, B. (2006). Building relationships for learning: the developing role of the teaching assistant. Support for Learning, 21 (4) 199-203

Gunter, H., Rayner, S., Thomas, H., Fielding, A., Butt, G., \& Lance, A. (2005). Teachers, time and work: findings from the Evaluation of the Transforming the School Workforce Pathfinder Project. School Leadership and Management, 25 (5) 441-454

Hammett, N. \& Burton, N. (2005). Motivation, Stress and Learning Support Assistants: an examination of staff perceptions at a rural secondary school. School Leadership and Management, 25 (3) 299-310

Hayes, B., Richardson, S., Hindle, S., \& Grayson, K. (2011). Developing teaching assistants' skills in positive behaviour management: an application of Video Interaction Guidance in a secondary school. Educational Psychology in Practice, 27 (3) 255-269

Higgins, H. (2009). A study exploring the influences of training on teaching assistants' learning, behaviour and self-efficacy. Unpublished doctoral dissertation. University of Nottingham, Nottingham

Hutchings, M. (1997). The impact of a specialist teacher assistant training programme on the development of classroom assistants. Early Years. 18, 35-39

Kitzinger, J. (1995). Education and debate Qualitative Research: Introducing focus groups. British Medical Journal. 311, 299-302

Krueger, R. A., \& Casey, M. A. (2000). Focus Groups: A Practical Guide for Applied Research. London: Sage Publications

Lacey, P. (2001). The Role of Learning Support Assistants in the Inclusive Learning of Pupils with Severe and Profound Learning Difficulties. Educational Review, 53 (2) 157 - 167

Lave, J. and Wenger, E. (1991) Situated Learning. Legitimate Peripheral Participation. Cambridge. Cambridge University Press. 
Miller, A (2003). Teachers, Parents and Classroom Behaviour. A Psychosocial Approach. Maidenhead: Open University Press.

Moran, A., \& Abbott, L. (2002). Developing inclusive schools. The pivotal role of teaching assistants in promoting inclusion in special and mainstream in Northern Ireland. European Journal of Special Needs Education, 17 (2) 161-173

Morris, E. (2001). Professionalism and trust: a speech by the Rt Hon Estelle Morris MP Secretary of State for Education and Skills to the Social Market Foundation. London: HMSO

Muijs, D., \& Reynolds, D. (2003). Student Background and Teacher Effects on Achievement and Attainment in Mathematics: A Longitudinal Study. Educational Research and Evaluation, 9 (3) $289-314$

Opfer, V.D. and Pedder, D. (2011) Conceptualizing Teacher Professional Learning Review of Educational Research September 81, 3, 376-407.

Penrose, A., Perry, C., \& Ball, I. (2007). Emotional intelligence and teacher self-efficacy: The contribution of teacher status and length of experience. Issues in Educational Research, 17

(1) $107-126$

Quinones, M. A. (1997). Contextual influences on training effectiveness. In M. A. Quinones and A. Ehrenstein (eds) Training for a rapidly changing workplace: Applications of psychological research. London: American Psychological Association

Reeve, J. (2009). Understanding Motivation and Emotion. Hoboken, NJ: John Wiley and Sons Inc

Robson, C. (2002). Real world research. Oxford: Blackwell

Rotter, J. B. (1966). Generalized expectancies for internal versus external control of reinforcement. Psychological Monographs, 80, 1-28

Russell, A., Blatchford, P., Bassett, P., Brown, P., \& Martin, C. (2005) The views of teaching assistants in English Key Stage 2 class on their role, training and job satisfaction. Educational Research, 47 (2) 175-189

Sachs, J. (1988). Teacher preparation, teacher self-efficacy and the regular education initiative. Education and Training in Mental Retardation, 2 (4) 237-332

Shapiro, D. H., Schwartz, C. E., \& Astin, J. A. (1996) Controlling ourselves, controlling our world: Psychology's role in understanding positive and negative consequences of seeking and gaining control. American Psychologist, 51 1213-1230

Skaalvik, E. M., \& Skaalvik, S. (2007). Dimensions of teacher self-ffficacy and relations with strain factors, perceived collective teacher efficacy and teacher burnout. Journal of Educational Psychology, 99 (3) 611-625

Skaalvik, E.M. and Skaalvik, S. (2010) Teacher self-efficacy and teacher burnout: A study of relationsTeaching and Teacher Education 26, 1059-1069

Soltys, L. K. (2005). A study of the relationship between teacher self-efficacy, the tendency to blame parents for child problems and parent-teacher collaboration activities in elementary schools. Dissertation Abstract International Section A. Humanities and Social Science, 65 (10-A) p 3695

Swann, W. \& Loxley, A. (1998). The impact of school-based training on classroom assistants in primary schools. Research Papers in Education. 13, 141-160

Swartz, L., de la Rey, C., \& Duncan, N. (2004). Psychology an Introduction. Oxford: Oxford University Press

Taylor, V., and Gulliford, A. (2011) Parental perspectives on nurture groups: the potential for engagement. British Journal of Special Education, 38, 2, 73-82.

Tebbs, T. J. (2001). Assessing teachers' self-efficacy towards teaching thinking skills. Dissertation Abstracts International Section A. Humanities and Social Sciences, 61 (12-A) p 4666

Tobin, T. T., Muller, R. O., \&Turner, L. M. (2006). Organisational learning and climate as predictors of self-efficacy. Social Psychology of Education, 9, 301-319

Turner, K. M. T., Nicholson, J. M., Sanders, M.R. (2011) The Role of Practitioner Self-Efficacy, 
Training, Program and Workplace Factors on the Implementation of an Evidence-Based Parenting Intervention in Primary Care. The Journal of Primary Prevention, 32,2,95-112

Vaughn, S., Jeanne Shay Schumm, J., \& Sinagub, J. (1996). Focus group interviews in education and psychology. London: Sage

Wade, K. K. (2003). Preservice and inservice teachers' knowledge and use of functional behaviour assessment and intervention for problem behaviors. Dissertation Abstracts International Section A. Humanities and Social Sciences, 64 (6-A) p 1989

The Warnock Report (1978). Special educational needs: Report of the Committee of Enquiry into the education of handicapped children and young people. London: HMSO

Webster, R., Blatchford, P., \& Russell, A. (2012). Challenging and changing how schools use teaching assistants: Findings from the Effective Deployment of Teaching Assistants project. School Leadership and Management, 33(1), 78-96 


\begin{tabular}{|c|c|}
\hline Source & Mode of induction \\
\hline $\begin{array}{l}\text { Enactive mastery experiences/ } \\
\text { performance accomplishment- } \\
\text { having a successful firsthand } \\
\text { experience of the task }\end{array}$ & $\begin{array}{l}\text { 1. Participant Modelling } \\
\text { 2. Performance Desensitisation } \\
\text { 3. Performance Exposure } \\
\text { 4. Self-instructed Performance }\end{array}$ \\
\hline $\begin{array}{l}\text { Vicarious experiences- watching } \\
\text { someone having success with a } \\
\text { task }\end{array}$ & $\begin{array}{l}\text { 1. Live-modelling } \\
\text { 2. Symbolic modelling }\end{array}$ \\
\hline $\begin{array}{l}\text { Verbal persuasion- someone } \\
\text { trying to verbally persuade a } \\
\text { person to do a task }\end{array}$ & $\begin{array}{l}\text { 1. Suggestion } \\
\text { 2. Exhortation } \\
\text { 3. Self-instruction } \\
\text { 4. Interpretative Treatments }\end{array}$ \\
\hline $\begin{array}{l}\text { Physiological and affective states- } \\
\text { emotional feelings about a task }\end{array}$ & $\begin{array}{l}\text { 2. Attribution } \\
\text { 3. Relaxation, biofeedback } \\
\text { 4. Symbolic Desensitisation } \\
\text { 5. Symbolic Exposure }\end{array}$ \\
\hline
\end{tabular}

Table 1: The different sources and modes of induction of self-efficacy (from Bandura, 1977) 


\begin{tabular}{|c|c|c|c|}
\hline \multicolumn{2}{|c|}{$\begin{array}{l}\text { Training methods and elements of } \\
\text { training }\end{array}$} & $\begin{array}{l}\text { Sources of } \\
\text { information }\end{array}$ & Modes of induction \\
\hline \multirow[t]{5}{*}{$\begin{array}{l}\text { Coach Consult } \\
\text { method }\end{array}$} & Needs assessment & Enactive mastery & $\begin{array}{l}\text { Self instructed } \\
\text { performance }\end{array}$ \\
\hline & Training & $\begin{array}{l}\text { Vicarious experience } \\
\text { Verbal persuasion }\end{array}$ & $\begin{array}{l}\text { Live modelling } \\
\text { Suggestion }\end{array}$ \\
\hline & Implementation & Enactive mastery & $\begin{array}{l}\text { Performance } \\
\text { desensitisation } \\
\text { Performance exposure }\end{array}$ \\
\hline & Recap and Reflection & $\begin{array}{l}\text { Enactive mastery } \\
\text { Physiological arousal }\end{array}$ & $\begin{array}{l}\text { Self- instructed } \\
\text { performance }\end{array}$ \\
\hline & Adaptive curriculum & Enactive mastery & $\begin{array}{l}\text { Self instructed } \\
\text { performance }\end{array}$ \\
\hline INSET Training & Training & $\begin{array}{l}\text { Vicarious experience } \\
\text { Verbal persuasion }\end{array}$ & $\begin{array}{l}\text { Live modelling } \\
\text { Suggestion }\end{array}$ \\
\hline
\end{tabular}

Table 2: Sources of information and modes of induction for the coach consult method and the INSET training approach 


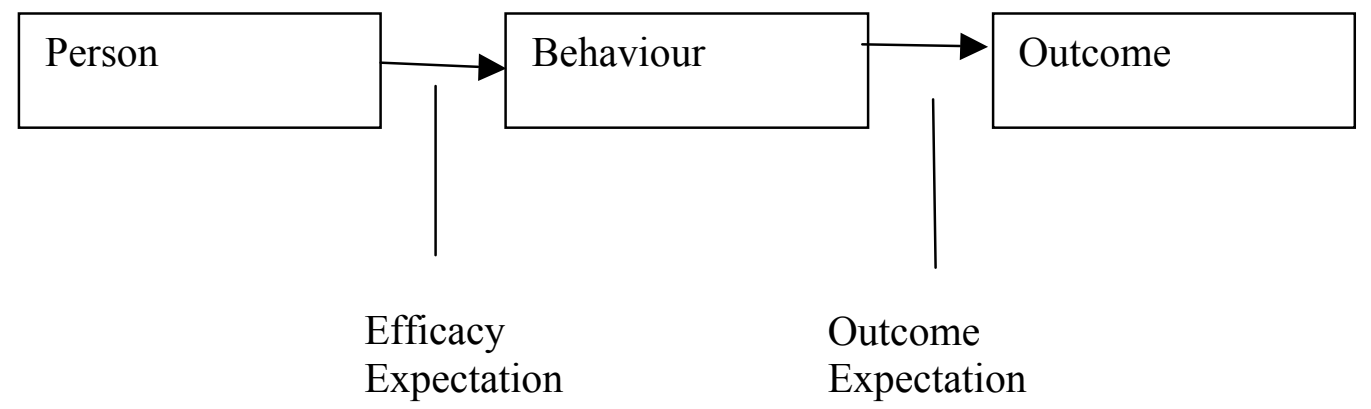

Figure 1: Bandura's (1977) model of perceived self-efficacy as a process made of the factors; efficacy expectation and outcome expectation 


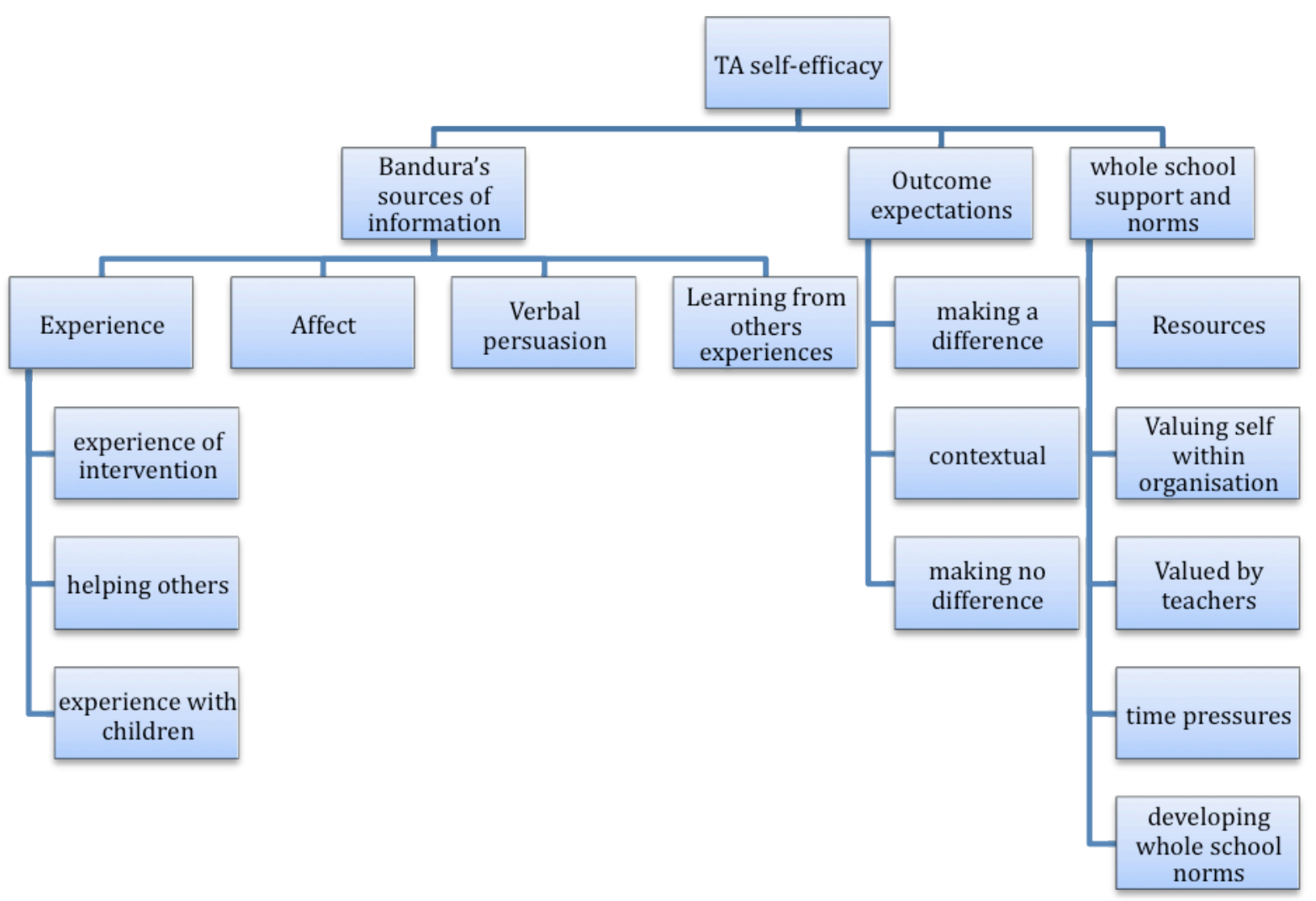

Figure 2: Thematic map for factors affecting TA self-efficacy 


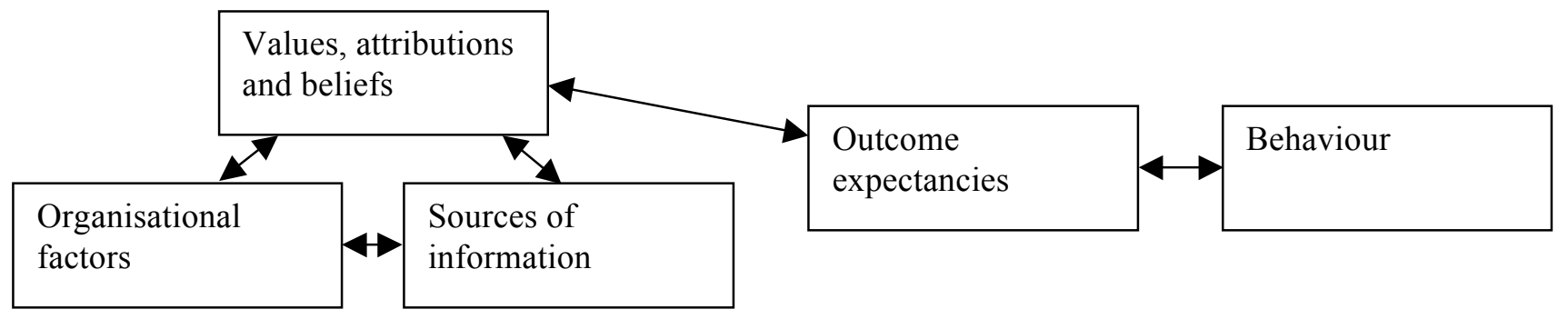

Figure 3: Model combining factors influencing TA self-efficacy 